\title{
Method for analyzing students' utilization of prior physics learning in new contexts
}

\author{
Dyan L. McBride, ${ }^{*}$ Dean Zollman, and N. Sanjay Rebello \\ Department of Physics, Kansas State University, Manhattan, Kansas 66506, USA
}

(Received 19 November 2008; revised manuscript received 24 March 2010; published 8 July 2010)

\begin{abstract}
In prior research, the classification of concepts into three types-descriptive, hypothetical and theoreticalhas allowed for the association of students' use of different concept types with their level of understanding. Previous studies have also examined the ways in which students link concepts to determine whether students have a meaningful understanding of principles of evolution. In this study, we build on our previous work that seeks to examine how students use prior knowledge in new situations and context, as well as present an adaptation of concept and concept-link categorization previously used in biology education research. In this adaptation, concepts are categorized on the basis of the observability of the concept exemplars and are shown to be dependent upon the knowledge level of the student. We use this categorization method to examine how students use prior knowledge when presented with an opportunity to apply physics in a new context, namely, wavefront aberrometry. Results indicate that students primarily utilize lower-level concepts, which is in agreement with previous research findings. We also found that students are able to create links between different levels of concepts, and that the type of links created can give insight to how deeply they understood the physics of the new context.
\end{abstract}

DOI: 10.1103/PhysRevSTPER.6.020101

PACS number(s): 01.40.-d

\section{THEORETICAL PERSPECTIVES AND LITERATURE REVIEW}

\section{A. Concepts and conceptual change}

Because students come to the study of physics with a conceptual view of the world, the process of learning physics is frequently characterized as conceptual change. The conceptual change literature is vast and a full review is beyond the scope of the present work. Duit's bibliography [1], for example, contains about 8400 entries on research related to concepts and conceptual change in science. Our efforts here are motivated by the desire to better understand how students think about concepts in physics. This understanding can lead to a deeper view of how students organize and construct their physics knowledge. Our study has its foundation in the approaches of Mayer [2], whose overview connects the discussion of knowledge in pieces to the work on conceptual changes, and the review by Duit and Treagust [3] which discusses the classical and modern view of conceptual change.

Duit and Treagust [3] describe classical conceptual change models as ones in which teacher made "students' alternative frameworks explicit prior to designing a teaching approach consisting of ideas that do not fit the students' existing ideas and thereby promoting dissatisfaction. A new framework is then introduced based on formal science that will explain the anomaly." They note, however, that while these teaching methods were superior to more traditional ones, they seldom resulted in students' previous conception being "completely extinguished and then replaced by the science view. Indeed, most studies show that the old ideas stay alive in particular contexts." Duit and Treagust go on to suggest that a contemporary view of conceptual change requires

\footnotetext{
*Present address: Department of Physics, Mercyhurst College,
} Erie PA 16546. many different perspectives, including investigations of affective factors. Part of the multiple viewpoints includes understanding how students view competing or complementary concepts. A focus of our study is to investigate how students connect various concepts in an attempt to apply physics to a novel (to them) situation.

For much of the present research in physics education we consider knowledge in smaller units than the concepts which are discussed by Duit and Treagust. diSessa [4,5], Hammer $[6,7]$, Minstrel [8], and Redish [9,10] have all alluded to the notion that students do not have well developed or coherent mental models that they use, but rather activate pieces of knowledge. In turn, the activation of these pieces depends upon the problem or application context. diSessa [4] points out these pieces themselves, which he calls p-prims, may not be correct or incorrect, but rather they may be correctly or incorrectly activated in a particular context.

Recent findings also demonstrate that students frequently make up answers on the spot $[11,12]$. Often students combine various bits of knowledge and dynamically choose, apply and reject those pieces as they think through the answer to a question-for example, as they may do during a clinical interview or while responding to a test question. Sometimes, students may even combine seemingly disparate ideas to form a hybrid mental model [11] that "works," at least for the students, in a given set of contexts. Based on these findings, several researchers have begun to focus on the process by which students construct knowledge. The value of attending to the pieces of knowledge that are activated by students is a useful perspective to adopt because it allows us to develop instructional strategies that help students activate and build on the productive bits of knowledge that they already possess while inhibiting the activation of unproductive pieces of knowledge.

Toward the goal of describing the process by which learners combine smaller grain sized knowledge elements to create larger knowledge structures, diSessa has proposed another knowledge structure-the coordination class. A 
TABLE I. Four views of conceptual change based on Mayer.

\begin{tabular}{|c|c|c|c|c|}
\hline & $\begin{array}{l}\text { Change as synthesis } \\
\text { (Vosniadou) }\end{array}$ & $\begin{array}{l}\text { Change as replacement } \\
\text { (Chi and Roscoe) }\end{array}$ & $\begin{array}{l}\text { Change as organizing } \\
\text { knowledge in pieces } \\
\text { (diSessa) }\end{array}$ & $\begin{array}{l}\text { Change as tool } \\
\text { appropriation } \\
\text { (Ivarsson, Schoultz, } \\
\text { and Säliö) }\end{array}$ \\
\hline $\begin{array}{l}\text { What } \\
\text { changes }\end{array}$ & $\begin{array}{l}\text { Lerner's coherent } \\
\text { explanatory framework }\end{array}$ & $\begin{array}{l}\text { Learner's mental model } \\
\text { and concepts from } \\
\text { which it is built }\end{array}$ & $\begin{array}{c}\text { Learner's organization } \\
\text { of fragments in a } \\
\text { structure knowledge system }\end{array}$ & $\begin{array}{l}\text { Learner's use of } \\
\text { agreed upon concepts } \\
\text { (intellectual tools) and } \\
\text { representations } \\
\text { (physical tools) }\end{array}$ \\
\hline $\begin{array}{l}\text { Who } \\
\text { changes }\end{array}$ & $\begin{array}{l}\text { Learner as integrator } \\
\text { of new material }\end{array}$ & $\begin{array}{l}\text { Learner as a fixer } \\
\text { of concepts }\end{array}$ & $\begin{array}{c}\text { Learners are knowledge } \\
\text { organizers }\end{array}$ & $\begin{array}{l}\text { Interaction among } \\
\text { learners, tools and } \\
\text { other people }\end{array}$ \\
\hline $\begin{array}{l}\text { How does } \\
\text { change } \\
\text { occur }\end{array}$ & $\begin{array}{l}\text { By integrating } \\
\text { new knowledge into } \\
\text { existing model }\end{array}$ & $\begin{array}{l}\text { By identifying and } \\
\text { repairing "faulty" concepts }\end{array}$ & $\begin{array}{c}\text { By mentally reorganizing } \\
\text { ones knowledge }\end{array}$ & $\begin{array}{l}\text { By interacting with } \\
\text { others when one needs to } \\
\text { use the intellectual } \\
\text { and physical tools }\end{array}$ \\
\hline
\end{tabular}

coordination class, unlike a p-prim, is a large, complex system which is intended to constitute a model of a certain type of scientific concept. It involves "systematically connected ways of getting information from the world." [4] Coordination classes consist of two distinct elements: readout strategies and causal nets. Readout strategies are the set of methods by which any relevant information is gleaned from the world; causal nets are the collection of possible inferences that can be drawn from available information.

According to diSessa and Wagner [13], two processes are involved in constructing a coordination class-incorporation and displacement. Incorporation is the process of "recruiting elements of prior conceptualization into partial encoding of the new concept." This process occurs when learners make associations between their newly developing coordination class and prior knowledge. Displacement is the process of dismissing elements of prior conceptualization that may initially and inappropriately "take over" consideration of particular circumstances from a coordination class.

Hammer's [7] model of knowledge construction shares similarities to the coordination class model discussed above. He proposes that learners put together conceptual resources in understanding physical phenomena and concepts. Conceptual resources are small grain-size mental structures which can be thought of as "a unit of mind code." [14] Hammer likens these resources to chunks of computer codes that can be incorporated into programs to perform some function. As opposed to p-prims, resources are not just phenomenological but can also be epistemological and procedural. Thus, resources can be larger in grain-size than p-prims or facets. It is important to point out that Hammer's view of resource activation is in some ways different from other knowledge construction or processes in that it does not focus on negating or correcting inaccurate conceptions that are based on a learner's raw intuition. Rather it focuses on strategies to facilitate a learner's refining of their raw intuition. The process of refinement can involve activation and suppression of appropriate resources [14].
The theoretical approach taken in this work shares several similarities to the ideas of coordination classes and resource activation discussed previously by diSessa and Hammer, respectively. The above frameworks share the central idea that learners combine or connect smaller pieces of knowledge to construct larger knowledge structures. In the following sections, we describe how we adapt a theoretical framework that categorizes concepts and discuss how learners connect together these concepts to form larger grain-sized knowledge structures and demonstrate how the models of associative learning (such as those of diSessa and Hammer) can be integrated with models of concept categorization.

Mayer [2] connects the knowledge in pieces ideas with conceptual change by reviewing four models of conceptual change. For each of the models he addressed several questions. For the purpose of this study the three most interesting questions are: What changes? Who changes? And how does change occur? Table I highlights only a few of the viewpoints of conceptual change that stem from Mayer's work.

In diSessa's work, of course, the connection between knowledge in pieces as used in physics education research (PER) and conceptual change is most obvious. However, with each of the other models of conceptual change, the learner is organizing, activating or otherwise using pieces of knowledge. As Mayer demonstrates, these pieces of knowledge can be organized into concepts, which in turn need to be connected to one another so that the learner can apply them in novel contexts. In addition, the level of understanding of the application of physics involves the complexity of the concepts involved. Thus, by investigating the types of concepts used by learners and how the learners connect those concepts, we can understand better how they construct knowledge and apply it to new situations.

\section{B. Concept categorization}

In 1947, Northrop [15] explored the notion of logic and how it is applied in the sciences and humanities. He postu- 
lated that concepts require an assigned meaning, and that they can be divided into two types based on how the meaning is assigned. Concepts by intuition, the first category, include the concepts whose meaning is immediately realized. The second type, concepts by postulation, Northrop describes as having a meaning "which in whole or part is designated by the postulates of the deductive theory in which it occurs" (p. 83). As an example, consider the notion of "work." As defined in the context of physics, work is equal to the scalar product of force and distance (a concept by postulation). Thus, a person who holds a heavy object at the same height for a considerable length of time would be doing no physical work. However, in common language, they would likely argue otherwise-work in that context is somehow correlated with the effort exerted (a concept by intuition).

Following Northrop's work on how students construct meaning, Lawson, Abraham, and Renner [16] presented a framework for classifying concepts. The work of Lawson and colleagues was done in the context of biology, and as such all examples given are within the realm of biology. Concepts by apprehension have an immediately sensed input. Lawson et al. give the examples of cold, sharpness, and hunger. These concepts are felt and understood based on previous experience-if you've been cold once, you will immediately recognize the sensation of coldness again. However, cold can be context dependent: a resident of Jakarta is likely to have a much different concept of "cold" than someone from Toronto. Descriptive concepts seem equally as basic at first glance_objects such as table, processes such as eating, and relationships such as before or beside are descriptive concepts. Though these concepts may be considered common-sense because of how deeply they are ingrained, they must be learned through a series of interactions with the world. Finally, theoretical concepts are the highest level of concepts, and serve the purpose of explaining causal events. Lawson et al. explain that theoretical concepts require some sort of imagination or assumptions, and include ideas such as ghosts or magic.

Conceptual systems are networks of different types of concepts, and are classified as descriptive or theoretical [16]. Descriptive conceptual systems consist of concepts by apprehension and descriptive concepts only. They include no theoretical concepts, and therefore no explanation for causal events that cannot be readily perceived. Lawson et al. give the example of human anatomy (because of its descriptive and nonexplanatory nature). Theoretical conceptual systems, on the other hand, include theoretical concepts as well. They provide explanations for causal events, such as concepts in atomic theory and the theory of evolution.

While all three types of concepts are necessary for a complete categorization, concepts by apprehension seem to offer no meaningful contribution to understanding how students use prior knowledge (existing concepts) in new contexts and situations. Thus, further works by Lawson and colleagues focused primarily on descriptive and theoretical concepts. In addition, developmental theory including intellectual development was utilized to examine what types of concepts were exhibited by learners at different stages $[17,18]$. The operational definitions of concepts are in terms of the observability of their exemplars. For example, the concept of "chair" has many possible exemplars - a rocking chair, a desk chair, a folding chair, etc. It is the accessibility of these exemplars that guides the following definitions.

In a recent study, Lawson et al. [19] recognized a need for concepts which are intermediate, between descriptive and theoretical. Thus, the hypothetical concepts were introduced. In this enhanced approach descriptive concepts are the most basic and easiest to learn. Descriptive concept exemplars are easily and directly observable. Some exemplars are the food chain, carnivore, and nocturnal. The most advanced level of concepts, theoretical, are the most difficult to learn as their exemplars cannot possibly be observed. Air pressure, genes, and osmosis are exemplars of theoretical concepts. The intermediate concepts, hypothetical, are of a higher level than descriptive concepts, and as such are more challenging to learn. In biology, hypothetical concepts are those whose exemplars are not directly observable, but that one could imagine observing if it were possible to watch for an extended period of time. Some exemplars of hypothetical concepts are fossils, natural selection, and evolution.

The use and study of "exemplars" is common in cognitive psychology. In the exemplar approach new entities are classified according to how well they resemble other entities that have already been classified. By contrast, in the "prototype" approach all new entities are compared to an idealized or prototypical item [20]. Though these approaches are used in a slightly different way than in traditional cognitive psychology experiments, exemplar and prototype approaches are not contradictory, and in fact have many commonalities. McNamara and Miller [21], for example, support the idea that to form meaning one must realize exemplars in much the same way described by Lawson. Medin and Smith [22,23] have also done much work with the exemplar view of concepts as it relates to this body of work.

\section{Meaningful understanding}

Ausubel [24] characterized the distinction of meaningful versus rote learning in terms of the value of a learner's knowledge. He asserts that in order for the learning to be meaningful, the learner must be disposed to relating the new learning to something they already know, and that the learning is potentially significant to the learner, and not simply arbitrary information. In this perspective, a central tenant in meaningful understanding is therefore the ability for a student to use those meaningfully learned concepts (prior knowledge) in a new situation. Thus, his view aligns well with the goals for this study.

Using Ausubel's definition of meaningful learning as a basis, Nieswandt and Bellomo [25] expanded upon Lawson's work to analyze meaningful understanding of evolution in a 12th grade biology class. By looking not only at what types of concepts students utilized but also what types of connections they made between concepts, Nieswandt and Bellomo proposed that they could examine written answers to extended-response questions and assess the level of meaningful understanding which students displayed in the subject of evolution. They examined the following types of connec- 
tions: one-concept-level links such as descriptive-descriptive or hypothetical-hypothetical, cross-concept-level links such as descriptive-hypothetical and hypothetical-theoretical, and multi-concept-level links which connected all three types of concepts. Nieswandt and Bellomo postulate that true meaningful understanding is the ability to not only select and retrieve the necessary concepts, but to link those concepts appropriately. For their analysis of the student responses, they categorized the students' responses by examining both the level of the concepts used by the students and the links that the students made among the various concepts. This analysis led to an understanding of the students' thinking about the scenario that was presented.

To decide if the student was displaying "meaningful understanding," Nieswandt and Bellomo compared student responses to a complete response that a teacher might expect a student to make, and used these responses to determine whether students were able to select and link certain predetermined concepts. Their results indicated that students did not create enough links, or match closely enough the preferred response, to demonstrate the level of understanding expected in the correct answers.

\section{THIS STUDY}

The categorization scheme for concepts and the descriptions of concept links described above seem to provide the foundation for a complementary analysis method in which student understanding in physics can be explored. The initial purpose of this study is therefore to determine the feasibility of using the approach of Nieswandt and Bellomo [25] in the content area of physics to elicit information about how students utilize and link concepts when constructing an understanding of a new situation or context. Once feasibility is assured, this analysis will be used to answer the following research questions: What types of concepts do students use when constructing an understanding of a new context, and in what ways do they link those concepts? Once we have answers to these questions, we extend the data collection and analysis to look at grain sizes smaller than concepts to see if the same techniques can be applied to understand how students connect smaller pieces of knowledge to construct the concepts in a teaching-learning interview environment.

The categorization of concepts used by Lawson et al. and Nieswandt and Bellomo were developed for use in the context of biology. As such, two difficulties arise when attempting to utilize this paradigm in the realm of physics: the notion of time-dependant observability, and the relevance of expertise level. As illustrated below, we believe these conflicts can be resolved without affecting the essence of the paradigm.

First, the defining characteristics involve the observability of the concept with respect to the time required to see a change. This distinction is of little use in the context of physics, where the observability of an idea for the most part does not depend on how long one needs to watch. However, the notion of observability itself is a defining characteristic in physics - and observability is often distinguished by the apparatus, equipment and setup required for the observation.
Therefore, in physics, we propose the following operational definitions: Descriptive concepts are concepts with exemplars that can be directly observed, that is, by human senses. They require no special apparatus or change of setup. Hypothetical concepts are those with exemplars that could be observed if given appropriate apparatus or setup, but are not directly observable. Finally, theoretical concepts are those concepts with exemplars that cannot be observed, and no special apparatus or setup enables their observation.

The second issue that arises with the observability of concepts in physics is one of expertise. Consider the concept of "fossil" presented by Lawson et al. as an example of a hypothetical concept [19]. That fossil takes the same amount of time to be created regardless of who is "observing" the process, and therefore the concept is hypothetical to both novices and experts. As defined above, however, a concept's categorization in the context of physics is far more dependent on the level of expertise of the observer. Because a "concept" is actually a mental construct, and therefore not something that researchers can truly observe, it can be argued that no two people have an identical mental construct or "concept." However, it seems reasonable to assume that people who have similar mental models will have similar concepts and mental constructs. In this view, two experts in the field of physics will likely have similar mental constructs of an idea, and that their construct will be significantly different from the mental constructs of novices.

Consider the concept of a wavefront. A novice perhaps knows the textbook definition of a wavefront, but likely knows no way in which he could observe this phenomenon-any exemplars of the concept are therefore theoretical. On the other hand, an expert physicist understands wavefronts so deeply that observing an interference pattern is equivalent to observing the wavefronts of lightthe expert is able to use hypothetical exemplars of the concept. As a counter example, consider the notion of temperature. To an expert physicist, temperature is a measure of the average kinetic energy of the molecules of a substance-a concept with theoretical exemplars. However, to a novice physicist, temperature is how hot something is, which allows for descriptive exemplars of the temperature concept.

We believe these two examples illustrate the importance of considering the expertise-level when assigning concept categories. Because all participants in our study are introductory-level physics students, all of our concept categorizations will be made from the viewpoint of the student, not the expert.

This also illustrates the necessity of predefining each term. In the previous example of wavefronts, it must be clearly stated that the definition is from the basis of light waves, and not water waves. In the same respect, one is only able to accurately categorize the concepts by first considering the definition being used for the concept. In order to maintain consistency, the definitions of all concepts will also be taken from the point of view of the student, not the expert.

\section{METHODOLOGY}

\section{A. Context}

The specific context in which this study was conducted is an investigation of how students apply their knowledge of 


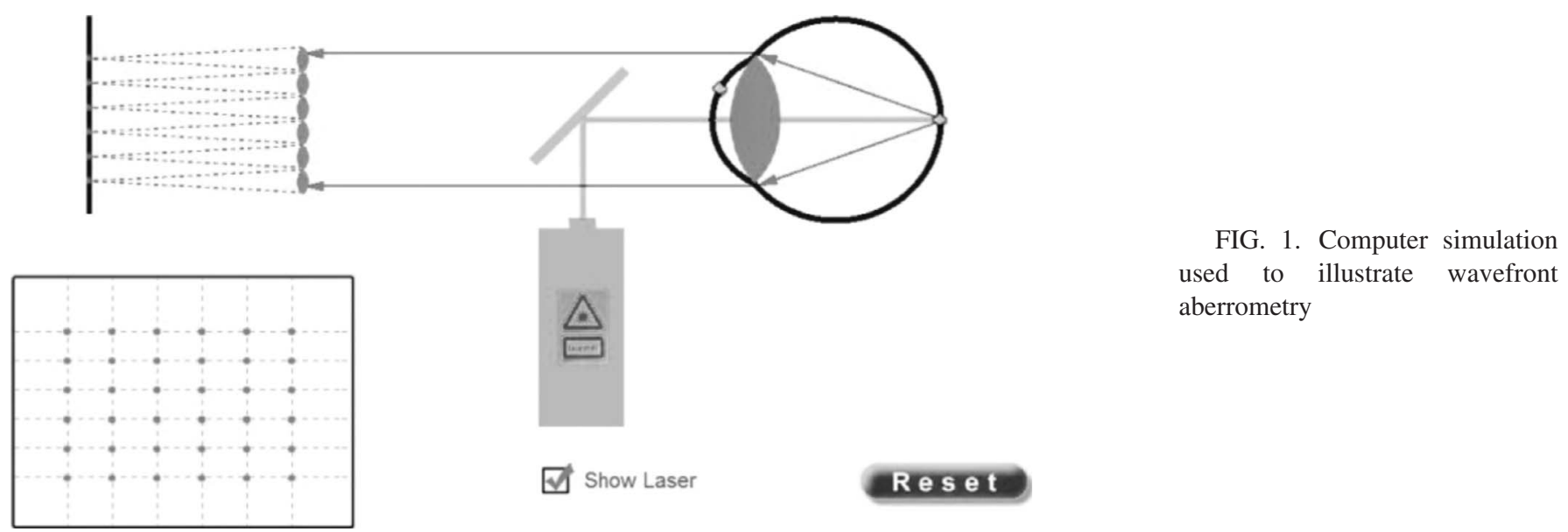

introductory physics to understand a new context, wavefront aberrometry, a relatively new method for diagnosing vision defects. Similar to the idea of "nearly novel" contexts presented by Sayre et al. [26], this new context allows for the investigation of knowledge transfer and sense-making in an unfamiliar situation. Wavefront aberrometry is novel in that it relies on the objective physical properties of light instead of the subjective responses of patients. Wavefront aberrometry is an appropriate context because its fundamentals can be understood using only the basic principles of geometric optics and further because it was an entirely new situation for all participants. These characteristics make wavefront aberrometry a good candidate for the study of knowledge construction in novel situations.

In a wavefront aberrometer a very low-power laser is shone into the eye and onto the retina; this acts as a secondary point source which emits light back through the front of the eye. As the light travels through the eye, it responds to all of the aberrations present in the ocular system. After the light leaves the eye, it passes through an array of very small lenses which cause the light to form a grid pattern. From that grid pattern, which is projected onto a CCD camera, optical information about the eye and its defects is obtained. Figure 1 shows a screenshot of a computer program used during the data collection, and provides a simple yet effective illustration of the process.

\section{B. Learning and teaching interviews}

The data for this study were collected primarily through use of learning and teaching interviews. This type of interview is a form of mock instruction which allows the researcher to focus on the dynamics of students' construction of knowledge [27]. In a learning and teaching interview, the researcher is not a passive observer. On the contrary, the researcher plays the role of instructor or facilitator by engaging the students, asking follow-up and probing questions, and providing scaffolding as necessary. The rich context of the learning and teaching interview is extremely useful for analyzing how students utilize and link concepts, primarily because of the researcher's ability to probe the knowledge level of the student and therefore more accurately categorize concepts. These learning and teaching interviews were conducted in both individual and group settings.
In one subset of the study, written extended-response questions were used in place of the learning and teaching interview. The work by Lawson et al. and by Nieswandt and Bellomo used written responses, so we were interested to see how written data and interview data compared in terms of richness of results. Also, analyzing written responses allows for a larger number of participants because of the time required to perform individual learning and teaching interviews.

\section{Participants}

The data for this study were collected over 2 years. The volunteer participants were enrolled in the second-semester of an introductory-level physics course at Kansas State University. Students were interviewed in four subsections, all of which were mutually exclusive. The first set of students contained 12 participants who were interviewed individually and had not yet received any formal instruction (preinstruction) in light and basic geometric optics; they are labeled as "PreInst-Indiv." The second set, which consisted of 18 participants, was interviewed twice. The first meeting allowed students to work through an exploratory lesson in which they used hands-on activities and computer simulations to learn about the light, vision, and the human eye using a reformed (active engagement) instructional protocol. The second meeting was a learning and teaching interview which followed the same protocol used in all other parts of this study; they will be labeled "RefInst-Indiv" to designate that they used the learning materials. The third and fourth sets were both postinstruction in light and basic geometric optics, as they had learned the material in a traditional lecture and laboratory setting. The third set was made up of five groups (13 total participants); the fourth set contained 30 participants who completed the protocol in the form of written extendedresponse questions. These sets are labeled as "TradInstIndiv" and "TradInst-Gr" for traditional instruction individuals and groups, respectively.

\section{Analysis}

Unlike studies described by Lawson and colleagues and Nieswandt and Bellomo [25], no exemplary answers were 
predetermined for this study. It should be noted that the data used in this study were initially collected for the purpose of a study of how students transfer their physics knowledge to medical contexts. However, after the previous study was complete, this application of concept categorization was realized. Because the larger purpose is to examine knowledge construction, the data were primarily taken from student responses to prediction and explanation tasks.

Before data analysis began, a panel was assembled in order to test the reliability of the categorization scheme for different concepts. Each rater was given a list of the concepts that included the definition of each concept as listed in a popular introductory-level physics textbook, and asked to rate each concept based on the given definition. Prior to any discussion, the reliability among 5 raters was a very low $59 \%$. The vast majority of discrepancies were of two types; the first type centered on the possible qualitative or quantitative nature of the concepts, and the second type highlighted the difference between expert and novice perceptions of the terms. These issues were easily dealt with, and the reliability rose to a far more acceptable $93 \%$.

The collected data includes students' thinking on a variety of aspects of the application of optics to wavefront aberrometry as a diagnostic tool. In this feasibility study we limit our analysis to the students' responses to the questions "What do you think will happen to the grid pattern if the eye is not perfectly shaped [nearsighted and farsighted]?," and "What do you think will happen to the grid pattern if the lens of the eye has a defect [aberration]?." Students were asked to make and explain predictions for each of these questions, to test their predictions, and reconcile any discrepancies.

\section{E. Example analysis}

To illustrate how raw data from the learning and teaching interviews were analyzed, we present the following excerpts.

Interviewer: What do you think would happen to the grid pattern if there was an aberration in the lens?

Student A: It would change somehow.

Interviewer: Okay-how do you think it would change?

Student A: Um, maybe it would be, um, bigger, or change in size maybe. Or change in the way-you know, clarity.

In this excerpt, Student A realizes that the aberration will likely cause a change in the grid pattern; however, the student is unable to connect ideas to help him describe that change. The descriptive concepts of size and clarity are used to describe the grid pattern, but these ideas are not linked to higher-level concepts.

A more rich example is presented next:

Interviewer: So what do you think would happen to the grid pattern if the lens of the eye had some sort of defect?

Student 1: I think instead of being like, right now you have one of these shapes [hexagon], like, I think that one of the points would move in toward center. Because it would, like instead of light going uniformly through [the lens] and creating this pattern, one would kind of like warp in this direction.

Student 2: Yeah, well, I think light would be hitting the smaller [array] lenses at a different angle because of the in- creased or decreased focal length of the lens [at the site of the defect].

In this excerpt, both students are making connections between concepts. Student 1 starts by describing the shape of the grid pattern and the position of the lights-descriptive concepts. He then relates this idea of shape to the theoretical concept of light going through the lens. In this respect, Student 1 has made a descriptive-theoretical link because he has connected these two ideas. Student 2 describes things differently-this time connecting the hypothetical concept of focal length with the theoretical concept of the light being bent at a different angle. This constitutes a hypotheticaltheoretical link.

\section{RESULTS}

By carefully examining all student responses as illustrated here, we were able to obtain quantitative data that describes student concept usage. Shown in Fig. 2 is a histogram illustrating student concept and link use. Individuals who completed our learning materials on the human eye (RefInstIndiv) and the sets from traditional-instruction classes (TradInst-Indiv and TradInst-Gr) used more concepts and created more links than the other two sets, and in fact the preinstruction individuals (PreInst-Indiv) were the lowest in every category (as we might expect). Upon examining the transcripts, we found that the students who were interviewed in groups routinely played off of each other's ideas and came to a consensus on the questions as a group and not individually. The success of the groups to create and link concepts together is supported by work done on student learning in small groups [28]. In order to look at the data more closely, we can separate out the two topics: Nearsightedness and farsightedness and Aberrations.

The results for nearsightedness and farsightedness show a decreased gap between RefInst-Gr and TradInst-Indiv in terms of the types of concepts they used, as well as in the links between concepts (Fig. 3). (Note that PreInst-Indiv participants were not directly asked this question, and data for that subset are therefore not reported.) The decrease in disparity among subsets is not so surprising because nearsightedness and farsightedness are common conditions-all students likely have some ideas about these defects, and therefore have more resources that they can apply to this situation [7]. Still, there is little evidence of the ability to link the higher-level concepts for any group, which indicates that their understanding is likely not complete or profound.

The most commonly used idea among all participants is that "the shape of the eye affects the spacing of the grid pattern," which is a link between two descriptive concepts. Also commonly used was another single-level descriptive link, "the shape of the eye affects how in-focus the dots are;" this link was most commonly used by the TradInst-Indiv participants, who tended to place a great deal of emphasis on how clear the image appeared. All of the hypothetical concepts used in answering this question were about the location of the focal point of the lens-the most common link was that "the shape of the eye changes the location of the focal point." Three TradInst-Indiv participants stated this relation- 


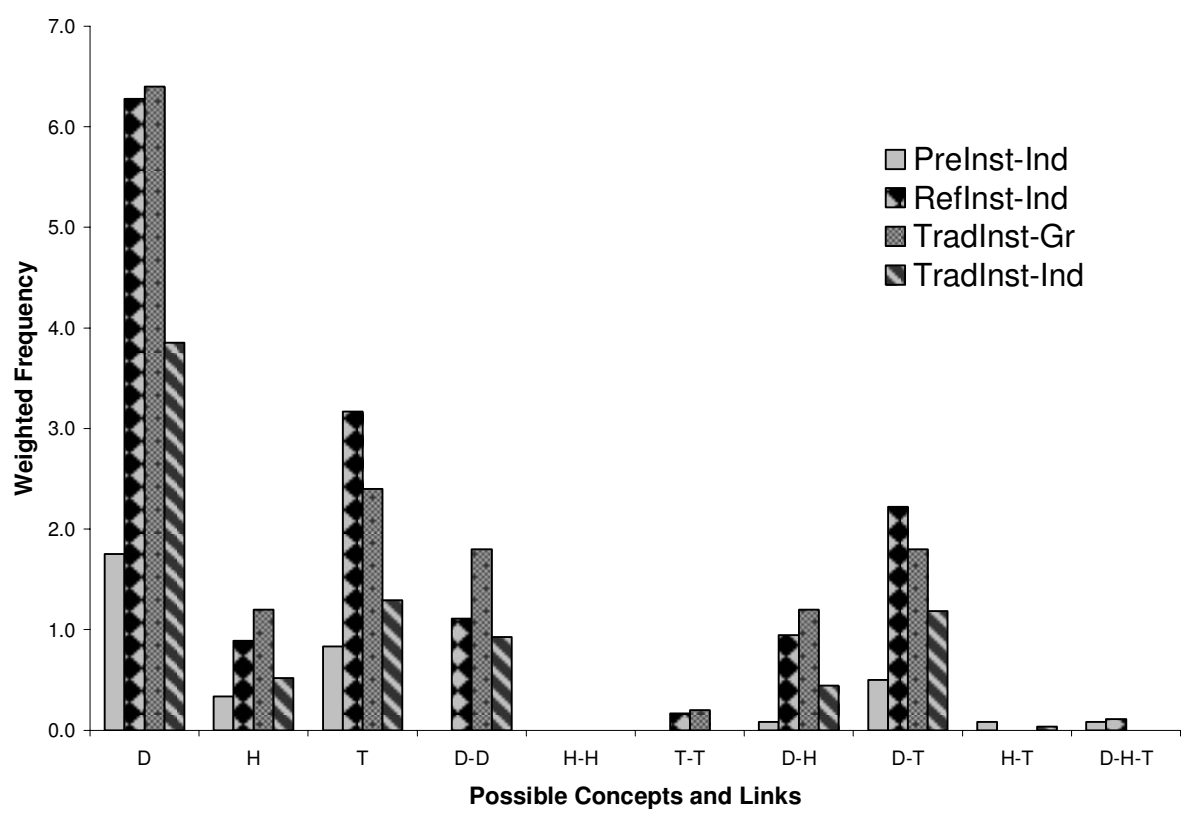

FIG. 2. Combined data, weighted by number of students

ship in terms of the variables in the thin lens equation by saying "the $d_{o}$ changes, so the $d_{i}$ must change also [since the focal point of the lens does not change]."

In the context of lens aberrations, we see from Fig. 4 that the gap between groups is much wider. The idea of aberrations in a lens was new to all subsets, and therefore we expect that they would have fewer resources to use in this context. However, we found that students use far more theoretical concepts than they did when discussing near and farsightedness; they were also able to link those theoretical concepts to descriptive concepts. Further examination revealed that these theoretical concepts dealt primarily with the propagation of light and were frequently linked to the visible changes on the grid pattern. From this perspective, the TradInst-Indiv and TradInst-Gr participants had more resources because they had learned about how light propagates in terms of lenses, mirrors, and refraction. A significant number of participants stated that "the aberration changes the direction of light through the lens" and even more were able to make the cross-level link that "the direction of light through a lens changes the position of the image." Hypothetical concepts were used most infrequently-again pertaining to the location of the focal point-and were rarely linked to other concepts of any type. Also noteworthy is that a couple of students did display the ability to create a multilevel link in this context, whereas they did not in the nearsighted and farsighted context.

Also of interest are the concepts which students stated, but failed to link together, as was illustrated in the first excerpt of the previous section. Figure 5 shows a weighted frequency analysis of these unlinked concepts. The PreInstIndiv participants display the most unlinked concepts,

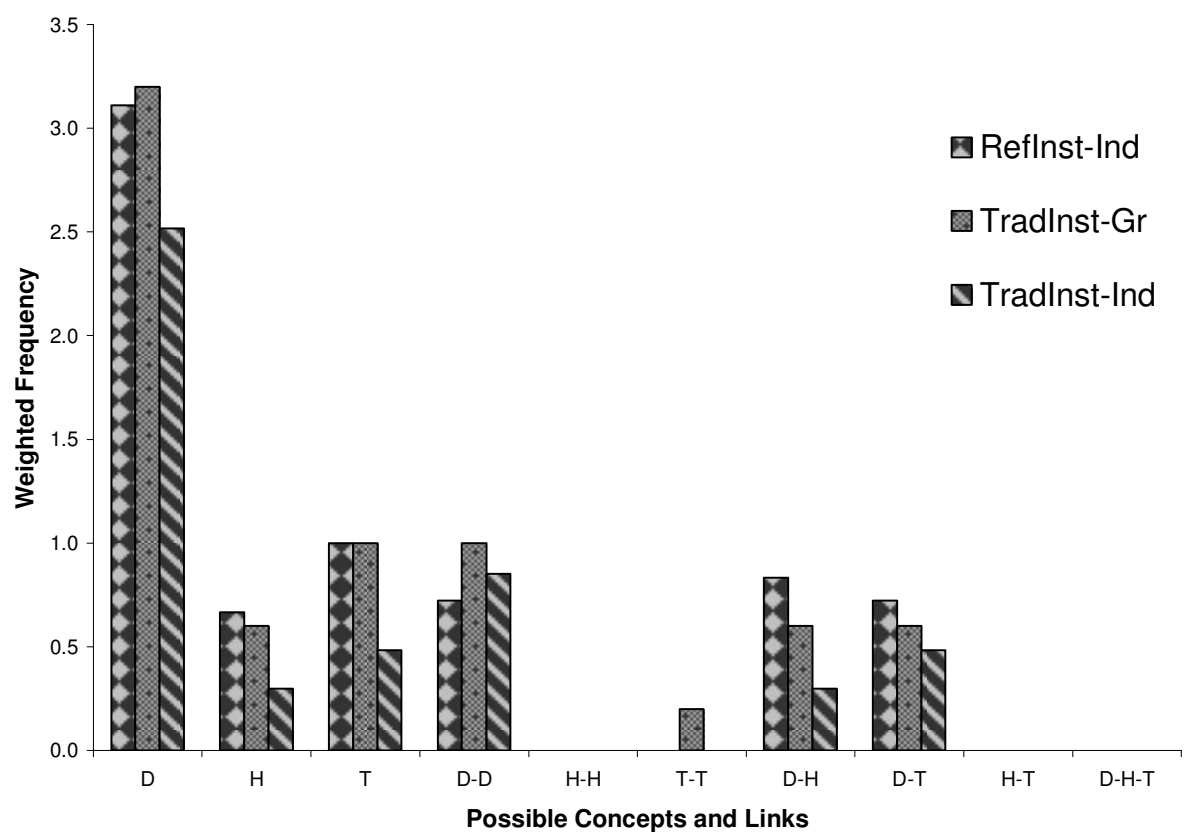

FIG. 3. Weighted data from nearsighted and farsighted concepts 


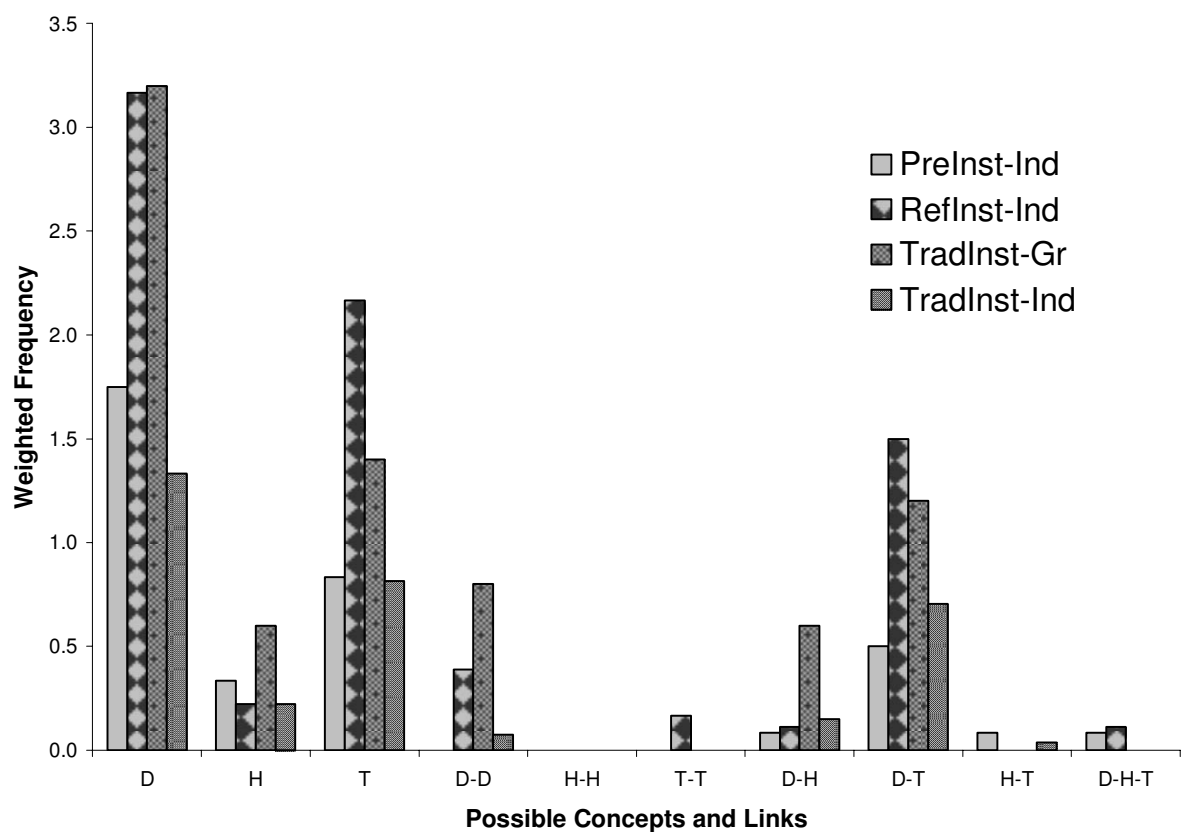

FIG. 4. Weighted data from aberration concepts whereas TradInst-Gr groups had no unlinked concepts. Initially surprising is that the vast majority of unlinked concepts are descriptive. This can be explained, particularly with the PreInst-Indiv participants, by examining the exact responses. During the prediction phases, we find that students tended to list some characteristics of the grid pattern that might change without explaining why they thought those changes would occur. In this respect, students were taking a "birdshot" approach to their predictions-toss out random predictions, and see what "sticks." Similarly, they simply stated the changes in appearance of the grid pattern during the observation phases without attempting to explain. Two examples of such statements are "the grid pattern gets blurrier," or "the dots move." The graph also shows that the majority of unlinked concepts were stated during the discussion of aberrations, and very few during the nearsightedness and farsightedness discussion. This is consistent with the earlier hypothesis that because students are more familiar with nearsightedness and farsightedness, they have more resources at their disposal than they do for the context of aberrometry.

\section{CONCLUSIONS}

From the data presented here, a few general conclusions can be drawn. One can immediately see that descriptive concepts were the most heavily used and that very few hypothetical concepts were utilized and linked. This result indicates that students relied most heavily on lower-level concepts and agrees with previously conducted studies by Lawson, et al. and Nieswandt and Bellomo. This result is not surprising. The students are learning about optics and vision for the first time, and thus we would expect their understand-

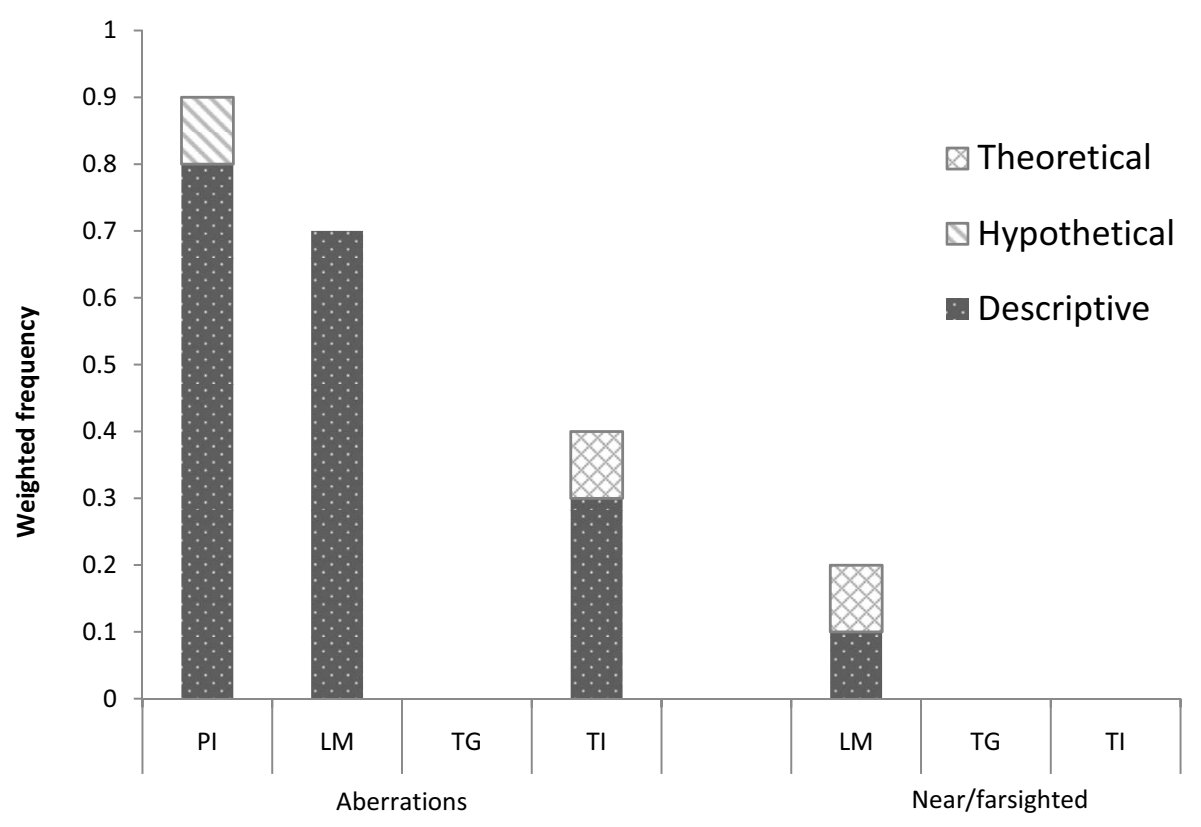

FIG. 5. Unlinked concepts used, sorted by participant set 
ing to be incomplete and for them to not realize the implications of what they have learned. The heavy use of descriptive concepts enforces that view.

During the discussion of nearsightedness and farsightedness, students were able to use a larger number of concepts than with the other topics under discussion. Our experience in listening to the students indicates that they had resources available to them in addition to those that they had obtained in their physics classes. Because of their experiences with eye examinations and discussions of vision issues in their everyday life, they were able to utilize these resources more completely and apply them to the tasks that we presented.

To understand wavefront aberrometry, the students utilized some of the resources about optics and waves and thus transferred their learning from other topics to this unfamiliar topic. Thus, students seemed to understand and transfer the material which was learned in other contexts to this new context. However, they relied most heavily on descriptive concepts. This reliance on descriptive concepts indicates that the depth of their understanding may be limited.

Students were also more likely to link lower-level concepts than to create higher-level or cross-level links. Again, this distinction is clear when examining nearsightedness and farsightedness as compared to aberrometry. While students were able to utilize some theoretical concepts in describing aberrometry, all students tended to use the same theoretical concept-light moving through a lens. The aberrometry data illustrate a clear distinction between those who had learned about how light propagates (TradInst-Indiv and TradInstGroup) and those who did not. A much greater variety of the concepts at all levels and more richness in the links were used when discussing nearsightedness and farsightedness than for wavefront aberrometry.

The type of both concepts and links help us understand the depth or meaningfulness of students' understanding. Based on an analysis of these data we conclude that they do not necessarily have as meaningful of an understanding of the wavefront aberrometry phenomena as they do of the simple eye defects. While this conclusion is not surprising, we find the analysis useful to support our intuition. By looking further at how the students link the concepts, we gain some insight into the differences.

Looking beyond the data presented here it is worthwhile to ask if this analysis technique has general value in under- standing how students apply their physics knowledge which is acquired through both the classroom and everyday life to new situations. The analysis provides evidence of clear distinctions among students who have different various learning experiences in physics. In our study, we investigated the resources that students with different backgrounds were able to utilize when applying physics to a new context. For vision defects, which are somewhat familiar to everyone, the differences among the groups were noticeable but somewhat smaller than for wavefront aberrometry. We also noticed differences in student use of concepts and reasoning (as displayed by the concept links) for different topics within the study. Thus, the method provides a good way to look at differences in student thinking when they apply physics to a new situation.

This method of concept analysis provides some significant insights into the ways in which students utilize previous learning. First, it provides a method for distilling a large body of data into simple, discrete pieces-the concepts. It also allows the researcher to view how those pieces are being connected-the concept links. Not only does it allow for the identification of which concepts students are using during the process of transferring learning, but it also enables us to see the level of understanding, the order in which the concepts are used and how the students associate the concepts with each other. This process affords the possibility of creating a record or map of how and when students activate and associate different resources. Thus, we can obtain a rather clear picture of the level of at which students are able to use previously learned material in new learning situation. By comparing the students' utilization of concepts with a desired level, we can identify appropriate types of scaffolding that can aid in the transfer process and help students develop an understanding that could better match our learning goals of deep or thorough understanding. At present we have used this approach to understand the differences. In the future we hope to take the analysis further and attempt to create scaffolding which can improve the meaningfulness for those areas where it seems to be lacking.

\section{ACKNOWLEDGMENTS}

This work has been supported by the National Science Foundation under Grants No. DUE 04-26754 and No. ESI055494.
[1] R. Duit, Students' and Teachers' Conceptions and Science Education, 2008: http://www.ipn.uni-kiel.de/aktuell/stcse/ stcse.html).

[2] R. E. Mayer, Understanding conceptual change, in Reconsidering Conceptual Change: Issues in Theory and Practice, edited by M. Limon and L. Mason (Kluwer, Norwell, MA, 2002), p. 101.

[3] R. Duit and D. F. Treagust, Conceptual change: a powerful framework for improving science learning, Int. J. Sci. Educ. 25, 671 (2003).

[4] A. diSessa and B. L. Sherin, What changes in conceptual change?, Int. J. Sci. Educ. 20, 1155 (1998).

[5] A. A. diSessa, Knowledge in Pieces, in Constructivism in the Computer Age, edited by G. Forman and P. B. Putfall (Lawrence Erlbaum, Hillsdale, NJ, 1988).

[6] D. Hammer, More than misconceptions: Multiple perspectives on student knowledge and reasoning, and an appropriate role for education research, Am. J. Phys. 64, 1316 (1996).

[7] D. Hammer, Student resources for learning introductory physics, Am. J. Phys. 68, S52 (2000).

[8] J. Minstrell, Facets of student's knowledge and relevant instruction, in Research in Physics Learning: Theoretical Issues 
and Empirical Studies, Proceedings of an International Workshop, edited by R. Duit, F. Goldberg, and Niedderer, IPN, Kiel, Germany, 1992, p. 110.

[9] E. F. Redish, Implications of cognitive studies for teaching physics, Am. J. Phys. 62, 796 (1994).

[10] L. C. McDermott and E. F. Redish, Resource Letter: PER-1: Physics Education Research, Am. J. Phys. 67, 755 (1999).

[11] Z. Hrepic, N. S. Rebello, and D. A. Zollman, Identifying students' modes of sound propagation, in Physics Education Research Conference, Boise, ID, 2002.

[12] Z. Hrepic, N. S. Rebello, and D. A. Zollman, Eliciting and representing hybrid mental models, in Annual Meeting of the National Association for Researchers in Science Teaching, Dallas, TX, 2005.

[13] A. diSessa and J. Wagner, What coordination class has to say about transfer, in Transfer of Learning from a Modern Multidisciplinary Perspective, edited by H. P. Mestre (Information Age Publishing, Greenwich, CT, 2005).

[14] D. Hammer and A. Elby, On the Form of a Personal Epistemology, in Personal Epistemology: The Psychology of Beliefs about Knowledge and Knowing, edited by B. K. Hofer and P. R. Pintrich (Erlbaum, Mahwah, NJ, 2002), p. 169.

[15] F. S. Northrop, The Logic of the Sciences and the Humanities (Macmillan, New York, 1947).

[16] A. E. Lawson, M. R. Abraham, and J. W. Renner, A theory of instruction: Using the learning cycle to teach science concepts and thinking skills, in Monographs of the National Association of Research in Science Teaching, Cincinnati, Ohio, 1989, Vol. 1, pp. 1-57.

[17] A. E. Lawson and J. W. Renner, Relationships of concrete and formal operational science subject matter and the development of the learner, J. Res. Sci. Teach. 12, 347 (1975).
[18] A. E. Lawson and L. D. Thompson, Formal reasoning ability and misconceptions concerning genetics and natural selection, J. Res. Sci. Teach. 25, 733 (1988).

[19] A. E. Lawson, S. Alkhoury, R. Benford et al., What Kinds of Scientific Concepts Exist? Concept Construction and Intellectual Development in College Biology, J. Res. Sci. Teach. 37, 996 (2000).

[20] M. Matlin, Cognition (Wiley, Hoboken, NJ, 2005).

[21] T. P. McNamara and D. L. Miller, Attributes of theories of meaning, Psychol. Bull. 106, 355 (1989).

[22] D. L. Medin and E. E. Smith, Concepts and concept formation, Annu. Rev. Psychol. 35, 113 (1984).

[23] E. E. Smith and D. L. Medin, Categories and Concepts (Harvard, Cambridge, MA, 1981).

[24] D. P. Ausubel, The facilitation of meaningful verbal learning in the classroom, Educ. Psychol. 12, 162 (1977).

[25] M. Nieswandt and K. Bellomo, Written Extended-Response Questions as Assessment Tools for Meaningful Understanding of Evolutionary Theory, J. Res. Sci. Teach. 46, 333 (2009).

[26] E. C. Sayre, M. C. Wittmann, and J. R. Thompson, Resource Selection in Nearly-Novel Situations, in Physics Education Research Conference, edited by J. Marx, S. Franklin, and K. Cummings (AIP Conference Proceedings, Madison, Wisconsin, 2003), Vol. 720, p. 101.

[27] P. V. Engelhardt and E. G. Corpuz, The Teaching Experiment - What it is and what it isn't, in Physics Education Research Conference, edited by J. Marx, S. Franklin, and K. Cummings (AIP Conference Proceedings, Madison, WI, 2003), Vol. 720.

[28] L. Springer, M. E. Stanne, and S. S. Donovan, Effects of Small-Group Learning on Undergraduates in Science, Mathematics, Engineering, and Technology, Rev. Educ. Res. 69, 21 (1999). 